\title{
Os limiares planetários, a Rio+20 e o papel do Brasil
}

\author{
Planetary boundaries, Rio +20 and the role of Brazil
}

\author{
Eduardo Viola ${ }^{1}$ \\ Matías Franchini ${ }^{2}$
}

\begin{abstract}
Resumo
Neste artigo consideramos os problemas ambientais globais dentro do conceito de limiares planetários, em convergência com os últimos avanços das ciências naturais. Nesse contexto, nosso objetivo é explorar o papel do Brasil na governança do espaço de operação seguro para a humanidade, avaliando como o país complementa o enorme capital ambiental físico que possui com ações políticas específicas orientadas para uma economia verde de baixo carbono (EVBC), tanto no âmbito doméstico quanto no internacional. Para atingir essa meta, em primeiro lugar discutimos conceitualmente a economia verde de baixo carbono como paradigma de desenvolvimento compatível com um espaço de operação seguro para a humanidade; em segundo lugar, analisamos a Rio+20 pelo prisma da governança global dos limiares planetários e pela atuação brasileira na Cúpula; e finalmente fazemos um diagnóstico da situação do Brasil em relação ao novo paradigma de desenvolvimento. Como conclusões da análise, destacamos a crescente distância entre a aceleração dos problemas da interdependência - especialmente a definição de um espaço seguro de operação para a humanidade - e os mecanismos globais de governança existentes, derivada de um sistema internacional bloqueado e dominado por forças conservadoras. O resultado frustrante da Rio+20 é evidência clara dessa defasagem. Nessa dinâmica, o Brasil tem o potencial para ser um ator central da governança dos limiares planetários, por seu vasto capital ambiental físico. No entanto, o mínimo avanço da EVBC no país degrada essa capacidade de agência, e o torna uma potência ambiental subdesenvolvida (underachiever environmental power).
\end{abstract}

Palavras-chave: Limiares planetários. Governança ambiental global. Brasil. Economia. Verde de baixo carbono.

\begin{abstract}
In this paper, we analyze the global environmental problems within the concept of planetary boundaries, along with the last advances in natural sciences. In this context, our aim is exploring the role of Brazil with regard to the governance of a safe operating space for humanity, evaluating how the country provides its huge physical environmental capital with specific policies directed towards a low carbon green economy (LCGE), both domestically and in the international domain. To achieve this goal, first, we discuss LCGE on a conceptual basis as a paradigm of development compatible with a safe operating space for humanity; second, we analyze Rio+20 from the perspective of the global governance of planetary boundaries and the Brazilian role in the Summit; and, finally, we provide a diagnosis of the Brazilian status with regard to the new paradigm of development. As conclusions from the analysis, we highlight the growing distance between the acceleration of interdependence problems - especially the definition of a safe operating space for humanity - and the current global governance mechanisms, derived from an international system which is blocked and dominated by conservative forces. The frustrating outcome of Rio+20 is a clear evidence of this gap. According to this dynamics, Brazil has the potential to be a key actor with regard to the governance of planetary boundaries, due to its huge physical
\end{abstract}

Artigo submetido em 15 de maio de 2012 e aceito para publicação em 17 de agosto de 2012.

1 Professor Titular do Instituto de Relações Internacionais da Universidade de Brasília; Pesquisador Sênior do CNPq; Coordenador da Rede de Pesquisa em Mudança Climática e Relações Internacionais da Universidade de Brasília. Endereço: Instituto de Relações Internacionais, Campus Universitário Darcy Ribeiro - Gleba A, Caixa Postal 04306, CEP 70919-970 - Brasília - DF, Brasil. E-mail: eduviola@gmail.com

2

Mestre e Doutorando em Relações Internacionais; membro da Rede de Pesquisa em Mudança Climática e Relações Internacionais da Universidade de Brasília. Endereço: Instituto de Relações Internacionais, Campus Universitário Darcy Ribeiro - Gleba A, Caixa Postal 04306, CEP 70919-970 - Brasília - DF, Brasil. E-mail: matifranchi@yahoo.com.ar 
environmental capital. However, the little advance of LCGE in the country hampers this action ability and turns it into an underachiever environmental power.

Keywords: Planetary boundaries. Global environmental governance. Brazil. Economy. Low carbon green.

\section{Introdução}

$\mathrm{Na}$ comunidade das ciências naturais, é cada vez mais consensual a ideia de que a crescente pressão antrópica sobre o sistema terrestre (ROCKSTRÖM et al., 2009) pode levar a uma mudança abrupta do ambiente global. Progressivamente, os humanos nos tornamos o principal vetor de mudança global sistêmica, que envolve a desestabilização de sistemas biofísicos críticos, com consequências deletérias ou mesmo catastróficas para o nosso bem-estar. Assim, durante os últimos 10 mil anos a Terra se manteve no domínio estável do Holoceno, isto é, certos parâmetros biogeoquímicos e atmosféricos oscilando dentro de um espaço relativamente pequeno. No entanto, com a revolução industrial, nossas ações estão efetivamente colocando uma série de processos centrais do sistema terrestre fora dos parâmetros de oscilação estável. Essa alteração marca a transição do Holoceno para uma nova era: a do Antropoceno. O conceito de Antropoceno ilustra os dois processos centrais acima referidos: o fator antrópico como principal vetor de mudança ambiental sistêmico, e o desvio - com enormes consequências potenciais - dos padrões estáveis do Holoceno.

Considerando essa situação, a ciência avançou na identificação de fronteiras planetárias dentro das quais a humanidade poderia operar de forma segura em referência ao funcionamento do sistema terrestre. Atravessar essas fronteiras implicaria entrar numa zona de risco de disrupção ambiental sistêmica. A noção de fronteiras planetárias aparece como uma nova forma de abordar a sustentabilidade, não já de forma isolada e localizada (análises setoriais de limites ao crescimento e minimização de externalidades negativas) como a abordagem ambiental clássica, mas de forma global, sistêmica. Dessa forma, nove fronteiras planetárias são identificadas, sete das quais são passiveis de serem quantificadas: mudança climática; acidificação dos oceanos; ozônio; ciclo biogeoquímico do nitrogênio e fósforo; uso da água doce; mudanças no uso da terra; biodiversidade; poluição química; e concentração de aerossóis na atmosfera. Três dessas nove fronteiras planetárias já foram ultrapassadas: mudança climática, taxa de perda de biodiversidade e ciclo do nitrogênio.

A discussão sobre o espaço de operação segura da humanidade relaciona-se de forma muito próxima com o debate clássico da ecologia global a respeito do impacto da dinâmica populacional sobre o futuro do planeta. Esse impacto é medido por meio de uma equação que relaciona o número de humanos vivos, o nível de consumo e o caráter da tecnologia (destrutiva ou benigna). Com níveis moderados de consumo e disseminação generalizada de tecnologias sustentáveis, o sistema terrestre é capaz de suportar crescentes números de habitantes. No entanto, a atual progressão dessa equação - crescimento populacional, crescimento do consumo per capita e predomínio de tecnologias não sustentáveis (poluentes, carbonizantes e intensivas em uso de água e recursos naturais) - é incompatível com a manutenção dos parâmetros estáveis do Holoceno.

Existe mais um fator de extrema relevância, que deve ser considerado em qualquer reflexão sobre a dinâmica civilizatória atual: a aceleração da história. O processo é, em primeira medida, social e cultural, e implica um aumento drástico da velocidade dos processos sociais. É também um fenômeno físico, na medida em que as atividades humanas mudam a própria fisionomia do planeta em um ritmo nunca antes visto: consumo de recursos, destruição de biodiversidade, desestabilização do sistema climático temperatura, contaminação das águas, etc. A rapidez das inovações tecnológicas, especialmente na área de informação, destaca-se aqui de forma significativa. Para o indivíduo, a extrema velocidade da realidade que o circunda acaba por afetar seu funcionamento, colocando desafios que tendem a alterar os mecanismos de processamento de informação e os mecanismos de tomada de decisão. 
A administração das fronteiras planetárias nesse contexto requer um desafio profundo para a governança em todos os níveis. A governança global apresenta-se especialmente exigida na medida em que os limiares planetários se tornam global commons, embora de diversa espécie. Sem elevados níveis de cooperação internacional, é impossível definir e proteger um espaço de operação seguro para a humanidade.

Essa cooperação confronta-se com um obstáculo central: a disrupção do sistema terrestre é incremental (combinando processos rápidos e lentos) e seus efeitos mais evidentes estão localizados em uma escala temporal ampla. No entanto, a humanidade apenas reage a ameaças imediatas muito tangíveis ou à imoralidade extrema e, como consequência, as instituições sociais estão criadas para funcionar dentro do horizonte do curto prazo. Ao contrário, o fundamento do desenvolvimento sustentável - definido cada vez mais em referência a um espaço de operação segura para a humanidade - está no longo prazo.

A Rio+20 manifesta-se como evidência clara dessa defasagem entre crise sistêmica, que já é quase evidente; consciência pública global sobre o problema, que se expande progressivamente; e resposta política extremamente conservadora e ineficiente. A Cúpula foi um fracasso desde o ponto de vista da evolução dos mecanismos cooperativos para governar o ambiente global nos últimos 20 anos, e um enorme fracasso se consideradas as evidências científicas sobre a degradação do sistema terrestre acumuladas neste período.

Esse deficit da governança ambiental é, no entanto, reflexo do bloqueio da governança da ordem internacional, que está dominada por forças conservadoras e soberanistas. Esse sistema internacional de hegemonia conservadora (VIOLA, FRANCHINI e LEMOS RIBEIRO, 2012) torna-se incapaz de dar resposta aos problemas derivados da profunda interdependência das sociedades contemporâneas, que demandam como nunca arranjos cooperativos para serem solucionados. O sistema tradicional de governança universal - ancorado no sistema das Nações Unidas - manifesta cada vez mais sua obsolescência; ao mesmo tempo, o experimento com novos mecanismos mais restritos e flexíveis como o G-20 tampouco consegue articular resposta.

O núcleo da questão é que uma arquitetura eficiente de instituições de governança global apenas é possível se os principais atores do sistema fizerem uma transição para o reformismo, aceitando limites ao seu poder e soberania para a construção de bens públicos globais de longo prazo. Esse é um cenário que não aparece como provável no curto e meio prazo.

$\mathrm{Na}$ discussão sobre o espaço de operação segura da humanidade, o caso brasileiro assume profunda relevância, tornando-se o país um agente central da governança dos limites planetários. No entanto, essa categorização - que na linguagem pré-limiares planetários chamava-se "potência ambiental" - necessita ser problematizada. O Brasil é uma potência ambiental apenas em termos de capital ambiental físico, no sentido de que possui uma base material de abundância de recursos naturais. Os fatos são bem conhecidos: a) estoque de carbono florestal mais importante do mundo ${ }^{3}$; b) maior estoque de biodiversidade do mundo; c) maior reserva de terras agriculturáveis e agrobusiness mais competitivo do mundo; d) terceiro maior estoque de água potável do mundo (após Rússia e Canadá); e) produção de etanol mais eficiente do mundo, e a segunda em quantidade produzida (atrás dos EUA - LAMERS et al., 2011); f) maior reserva de energia hidráulica no mundo, com capacidade para facilmente utilizá-la por ter indústria globalmente competitiva nesse campo.

No entanto, em termos de capital ambiental social, o Brasil integra os menos desenvolvidos entre as democracias consolidadas. Com mais intensidade do que em outras democracias, a lógica de curto prazo governa as instituições políticas e econômicas brasileiras, e nesse processo o baixo nível educacional da população tem papel fundamental. Essa profunda disfuncionalidade da política brasileira para lidar com a exigência de longo prazo que o desenvolvimento sustentável coloca dá o caráter do Brasil como potência

${ }^{3}$ O Brasil tem a segunda maior área florestal do planeta, atrás apenas da Rússia, cujas emissões originadas no desmatamento são inferiores devido à composição de suas florestas: uma parte importante é de floresta boreal e a outra é de floresta temperada. 
ambiental subdesenvolvida (underachiever environmental power), visto que a base material o posiciona como grande player, mas a dinâmica social pouco comprometida com o bem comum universal - espaço global de operação segura - mina as possibilidades de influenciar com maior intensidade a governança das fronteiras do planeta.

O nosso objetivo nesse artigo é explorar o papel do Brasil na governança do espaço de operação seguro para a humanidade, avaliando como o país complementa o enorme capital ambiental físico que possui com ações políticas específicas orientadas para uma economia verde de baixo carbono (EVBC), tanto no âmbito doméstico quanto internacional. Para isso dividimos o trabalho em três partes: na primeira discutimos conceitualmente a economia verde de baixo carbono como paradigma de desenvolvimento compatível com um espaço de operação seguro para a humanidade; na segunda, analisamos a Rio+20 pelo prisma da governança das fronteiras planetárias e atuação brasileira na Cúpula; e na terceira fazemos um diagnóstico da situação do Brasil em relação ao novo paradigma de desenvolvimento.

\section{Economia Verde de Baixo Carbono}

Há sérios obstáculos quando se pretende precisar uma definição de um tipo de economia que transcenda os paradigmas clássicos de crescimento e articule de forma abrangente e equilibrada o bem-estar presente e futuro da humanidade. O conceito de desenvolvimento sustentável, popularizado a partir de finais da década de 1980, é antigo e difuso. O conceito de economia de baixo carbono, desenvolvido a partir de 2006, é mais preciso e consistente, já que possui uma métrica clara (STERN, 2006). No entanto, é insuficiente como paradigma de desenvolvimento porque não considera de forma plena a problemática crescente da água, biodiversidade, e de outras fronteiras terrestres.

Acreditamos, no entanto, que uma definição de um novo paradigma deve considerar a discussão prévia sobre limiares planetários, de forma que o modelo de desenvolvimento global deva operar dentro das fronteiras do espaço seguro para a humanidade. Falamos assim de economia verde de baixo carbono (EVBC).

O baixo carbono torna-se a base dessa definição por várias razões: pelas características da problemática do clima (urgente, global, e com alto nível de reconhecimento por parte da opinião pública global em relação às outras fronteiras), pela métrica conhecida, pelas soluções disponíveis e pela sinergia com outros limiares planetários (Acidificação dos oceanos, biodiversidade, ciclo do nitrogênio, poluição química). Em termos mais específicos, a economia verde de baixo carbono envolve:

- redução de intensidade de carbono do PIB.

- redução das emissões de Gases de Efeito Estufa (GEE) per capita.

- uso eficiente das matérias-primas, alto nível de reciclagem no ciclo produtivo com progressivo abandono da obsolescência planejada no modelo de negócios (PACKARD, 1964);

- uso eficiente da água: redução da intensidade de água por unidade de PIB e uso racional múltiplo dos recursos hídricos;

- proteção da biodiversidade, utilização racional desses recursos na atividade econômica;

- diminuição do uso de fertilizantes na agricultura;

- maximização das energias renováveis na matriz energética;

- smart grid de energia que permita interligar eficientemente as diferentes formas de energia;

- estímulo ao transporte coletivo e à intermodalidade, privilegiando o abandono progressivo do transporte rodoviário; 
- igualdade republicana de oportunidades com promoção da redução do índice de Gini;

- estrutura tributária com crescente ênfase na tributação ao carbono, à poluição e ao desperdício de água, em substituição aos clássicos impostos ao capital e trabalho.

Em última instância, a economia verde de baixo carbono aponta para a prosperidade sem crescimento, mas observando a equidade no caminho. Assim, existem sociedades que não precisam crescer significativamente em termos materiais (economia, uso de energia e recursos naturais) porque já têm populações estabilizadas e um bom desenvolvimento da infraestrutura. O desafio para elas é transcender a lógica do crescimento tradicional e consolidar um processo de progressiva redução de emissões e pressão sobre as outras fronteiras da sustentabilidade.

Para os países de renda média, o crescimento no sentido de expansão material é ainda um imperativo, porque parte de suas populações não possuem os requisitos mínimos de sobrevivência. No entanto, para manter a humanidade dentro de um espaço de operação seguro, esse crescimento não pode ser intensivo em carbono, energia e recursos naturais, mas intensivo em tecnologia e fontes de energia limpas. Outro ponto fundamental é que uma parte destes países tem ainda taxa de fecundidade alta (acima de dois filhos por mulher) e deveriam desenvolver políticas de direitos reprodutivos e educação das mulheres que promovessem uma diminuição consistente e rápida da fecundidade ao patamar de reposição. Os países pobres enfrentam um desafio similar em termos de modelo de desenvolvimento e fecundidade, agravado, ainda, por problemas crônicos de governabilidade e corrupção que levam a alguns deles a se tornarem Estados falidos. Nesse caso, o apoio da comunidade internacional torna-se uma necessidade essencial.

Dessa forma, define-se a economia verde de baixo carbono em relação à determinação científica dos limites planetários, e em relação ao princípio de equidade, que, traduzido na prática, envolve espaço significativo de crescimento para os países pobres, algo menos para os países emergentes e crescimento próximo do zero para as sociedades desenvolvidas. Ao mesmo tempo, a EVBC tem como marco fundamental a referência apresentada na introdução a respeito do impacto do crescimento populacional sobre a estabilidade do sistema terrestre; desse modo, por exemplo, os diretos reprodutivos da mulher formam parte fundamental da discussão.

O novo paradigma de desenvolvimento assim definido impõe fortes desafios à governança, tanto doméstica como internacional. No plano interno envolve diálogo e articulação entre Estado, mercado e sociedade civil, cada um dos quais deve subordinar sua própria lógica de comportamento às exigências da estabilização do sistema terrestre. A articulação é particularmente demandante entre os diferentes níveis de governo nacional, estadual e municipal. A forma de organização burocrática do Estado também deve fazer a transição para a eficiência e a assimilação da economia verde do baixo carbono.

No plano internacional, e como já apontamos, a gestão do espaço seguro de operação para a humanidade não pode ser senão cooperativo para ser eficiente. Isso implica uma reforma profunda das atuais estruturas de governança global, como discutimos no próximo segmento.

\section{A Rio+20 e os Desafios da Governança Ambiental Global}

Para uma avaliação abrangente dos resultados da Rio+20 em relação à definição de um espaço seguro de operação para a humanidade, é necessário que efetuemos duas precisões prévias relativas ao seu contexto. A primeira envolve os limites do sistema de governança internacional criado após o fim da Segunda Guerra Mundial; a segunda diz respeito aos limites da governança ambiental no contexto desse sistema institucional de progressiva obsolescência. 
O papel da Organização das Nações Unidas (ONU) foi sempre menor que o almejado pelos seus fundadores no período de 1945-1989, mas, em parte, importante devido ao caráter bipolar e de confronto do sistema internacional e ao direito de veto das grandes potências no Conselho de Segurança (CS). A partir de 1990 e fundamentalmente desde 2007, seus limites são os de uma instituição internacional baseada no princípio da soberania nacional estrita, subdimensionada em termos de poder e recurso num mundo cada vez mais intensamente globalizado e marcado por fluxos transnacionais independentes dos Estados no contexto de aceleração geral dos processos físicos e sociais.

O reconhecimento da impotência histórica da instituição teve como resultado a experimentação com estruturas de governança mais restritas em termos de composição - porém universais em termos de problemática abordada. No entanto, elas também foram ainda limitadas em seus resultados, tal o caso do Grupo dos 20 (G-20) ou do Fórum das Grandes Economias para Energia e Clima (MEF - Major Economies Forum on Energy and Climate).

O problema central da governança global atual é que as instituições - internacionais e domésticas - criadas ao longo das últimas décadas não refletem o profundo nível de interdependência entre as sociedades. O desenvolvimento de problemáticas que apenas podem ser gerenciadas de forma cooperativa - como a crise climática ou financeira - demanda dos países crescentes níveis de compromisso com a governança global e, portanto, certa cessão de soberania. Sem embargo, apenas poucas sociedades no mundo estão dispostas a assumir esse tipo de empreitada; consequentemente, o sistema internacional encontra-se dominado por forças conservadoras.

Nesse sistema internacional de hegemonia conservadora, uma série de grandes atores estatais possui a capacidade de moldar o caráter da governança e, eventualmente, forçar a transição para um sistema com hegemonia de forças reformistas. São oito os agentes centrais da governança sistêmica (potências): três superpotências, Estados Unidos, China e União Europeia; e cinco grandes potências, Índia, Japão, Brasil, Rússia e Coreia do Sul. Enquanto a dinâmica das potências tender para o campo conservador - como de fato acontece -, é altamente improvável a possibilidade de uma reforma da governança que assimile e expresse o profundo nível de interdependência estrutural entre as sociedades e que incorpore como princípio reitor o espaço de operação segura para a humanidade.

Um avanço efetivo da governança global dentro do espaço de operação seguro para a humanidade exige, ao mesmo tempo, mudanças gerais no nível sistêmico e particulares na área ambiental específica.

A mais estrutural das demandas é o abandono progressivo do soberanismo ${ }^{4}$ por parte da maioria das sociedades, na medida em que os limiares planetários operam como global commons e aumentam de forma significativa a necessidade de articulação de respostas cooperativas. No momento, entre os grandes atores da governança global, o único claramente disposto a ceder poderes para instâncias supranacionais é a União Europeia (UE), seguido por Japão e Coreia do Sul com posições mais ambíguas. O resto dos países do G-20 é soberanista em graus variáveis, incluindo soberanismo extremo nos EUA, China, Índia, Rússia, Arábia Saudita e Argentina. Existem, no entanto, forças pós-soberanistas desenvolvidas na maioria das potências soberanistas: EUA, Canadá, Turquia, Indonésia, África do Sul, Brasil, México, Austrália e Argentina.

Entre as demandas específicas da área ambiental destacam-se as seguintes:

\footnotetext{
4 As categorias soberanismo/pós-soberanismo operam como extremos de um espectro e não como dicotomia. As forças soberanistas são aquelas que consideram que seu estado nacional não deve ceder parcialmente poderes para estruturas supranacionais e não admitem interferência externa em assuntos internos dos países, particularmente em referência a eles mesmos. As forças póssoberanistas já aceitaram ou estão dispostas a aceitar cessão de poderes para estruturas supranacionais e consideram que os assuntos internos de todos os países são passíveis de interferência. Em geral, a democracia opera como condição necessária para o pós-soberanismo, enquanto os grandes países (em termos de população, economia e território) tendem a ser soberanistas. De igual forma, a percepção de ameaças estratégico-militares tende a obstaculizar o desenvolvimento de lógicas pós-soberanistas.
} 
- criação de uma organização internacional ambiental com status superior a uma agência especializada da ONU e com poderes similares aos da Organização Mundial do Comércio (OMC), capaz de definir estratégias normativas globais para a estabilidade do ambiente na Terra; com poderes para monitorar a situação ambiental em cada um dos países, criticando publicamente aqueles que violem as normas; e com poder de polícia para implementar tratados e protocolos;

- internalização das fronteiras planetárias nos princípios e comportamento da OMC, do Fundo Monetário Internacional (FMI), Banco Mundial e Conselho de Segurança da ONU;

- reforma gradual da Assembleia Geral da ONU (AGNU) com vista a se transformar em um parlamento mundial representativo da população global, abandonando a atual representação de estados nacionais;

- criação de um Conselho de Desenvolvimento Sustentável (com poderes diferenciados mas equivalentes aos do Conselho de Segurança) no âmbito da AGNU, com poderes para atuar na área ambiental. Este conselho teria com a AGNU uma relação similar à que ela tem com o CS e seria formado por um grupo de membros permanentes sem poder de veto (de composição similar à do G-20) e um grupo de membros rotativos (BIERMANN et al., 2012).

No entanto, a área específica de governança ambiental passou por um processo de continuidade e ruptura ao longo dos últimos 40 anos, com um balanço final negativo em termos de construção de capacidades cooperativas e extremamente negativo se consideradas as exigências da estabilidade do sistema terrestre definidas pela ciência. Nesse caminho, a Cúpula de Estocolmo (1972) foi central na medida em que trouxe o problema ambiental para o sistema político internacional e articulou uma vaga declaração normativa sobre o desafio a ser enfrentado pela humanidade juntamente com a criação de um Programa específico dentro do sistema ONU, o Programa das Nações Unidas para o Meio Ambiente (PNUMA).

Construído sobre um acumulado de duas décadas, a Rio 92 foi o ponto mais alto de gestão cooperativa dos recursos ambientais comuns, não apenas porque gerou cinco instrumentos normativos relevantes (as Convenções de Mudança do clima, de Biodiversidade, e de Desertificação, a Declaração do Rio, e a Agenda 21), mas porque foi rodeada por um clima de otimismo em relação à evolução da governança global, nascido da desativação do conflito bipolar e expresso na ampla coalizão global que enfrentou o regime iraquiano após a invasão ao Kuwait. O valor da Rio 92 é alto, ainda que os instrumentos por ela criados não tenham refletido de forma suficiente o consenso científico da época e tivessem poucos efeitos práticos nos anos sucessivos.

A Cúpula de Johanesburgo de 2002 representou um fracasso profundo da governança cooperativa dos temas ambientais, já que não apenas não houve avanço significativo dos objetivos definidos 10 anos antes no Rio, bem como o contexto do encontro foi de aumento da conflitualidade sistêmica, resultado dos atentados terroristas do 11 de Setembro. Ainda, a cúpula sul-africana inaugurou neste campo a tradição de maquiar encontros multilaterais inúteis com a ficção de progresso.

Nos meses prévios a cada evento desse tipo, surgem declarações de extremo otimismo proferidas pelos negociadores profissionais - e amplificadas pela imprensa -, inflando as expectativas sobre os resultados das reuniões, o que representa mais uma ilusão ou resposta corporativa de parte daqueles que fazem das negociações sua vida e menos uma consideração baseada em fatos reais. Essa indústria de conferências é profundamente negativa porque não apenas não contribui à solução dos problemas, como também cria a ficção de que sua ineficácia é apenas transitória e não estrutural, obstaculizando o surgimento de outras instâncias de governança potencialmente mais adequadas.

Nesse contexto, a Rio+20 acabou honrando, de forma amplificada, a nociva tradição de cúpulas estéreis camufladas de avanço. A atuação da Conferência na área ambiental, climática e de desenvolvimento foi diluída em uma agenda por demais abrangente e difusa e, por vários motivos, acabou representando um 
retrocesso ainda maior que Johanesburgo com respeito à Rio 92 (Conferência das Nações Unidas sobre o Meio Ambiente e o Desenvolvimento - CNUMAD-92).

Em primeiro lugar, a Rio+20 tinha uma agenda menos ambiciosa do que sua antecessora, na medida em que não havia pretensão de estabelecer acordos de caráter legalmente vinculante, como a mencionada Convenção de Clima.

Em segundo lugar, a Rio+20 não conseguiu atingir os discretos objetivos a que se propôs: não houve nenhum avanço significativo na criação de um mecanismo de governança ambiental global, ou sequer um upgrade do limitado PNUMA. Nesse particular, a UE (liderada por uma coalisão franco-alemã-escandinavo-britânica) voltou a mostrar que é a vanguarda da governança global ao propor uma organização global do meio ambiente. Não obstante, a medida foi combatida com força por grande parte das maiores potências (EUA, China, Índia e Rússia), resistida com menos ênfase por Japão, Coreia do Sul e Brasil, e apenas com boa receptividade entre os países africanos - embora por motivos mais imediatistas do que o dos europeus: uma eventual sede em Nairóbi e a promessa de recursos para o desenvolvimento.

Tampouco houve acordo sobre uma definição relativamente consistente do conceito de economia verde, em boa medida porque os países do G77 assumem que ela virá servir aos interesses dos países desenvolvidos. E em referência aos objetivos de desenvolvimento sustentável, não apenas o processo de definição foi novamente diferido, como também não foram estabelecidos parâmetros para as negociações. Ainda, um elemento novo que parecia promissor no começo dos debates e que foi liderado pelo Brasil - um consenso normativo sobre governança dos oceanos incluindo a problemática da acidificação - acabou sendo esterilizado pela oposição soberanista de EUA, China e Rússia.

Finalmente, se considerada a evolução do estado do planeta nos últimos 20 anos, bem como os avanços da ciência em relação à identificação dos limiares planetários, a comunidade internacional reunida no Rio foi negligente ao ignorar deliberadamente um debate profundo em relação a esses temas, de forma que se observa cada vez mais a distância entre as necessidades do planeta e as estruturas de governança ambiental global. A eliminação da referência aos direitos reprodutivos no documento final da Cúpula, por pressão de países islâmicos, do Vaticano e de outros grandes países de tradição cristã, é mais uma amostra da defasagem entre política e ciência.

Em suma, e como balanço da Cúpula, a construção de governança global ficou mais comprometida, visto que a Conferência foi inútil do ponto de vista intergovernamental. Esse fracasso, apresentado como conquista por parte da maioria dos negociadores e alguns analistas, é ainda pior porque gera cinismo e cria a ficção de progresso. Uma cúpula séria, que colocasse as bases para uma cooperação eficaz, teria começado com uma abertura sincera a respeito das posições dos diversos atores, sem cair na tentação de procurar consensos mínimos que nada aportam à governança da área. O problema é que até os agentes reformistas, como a UE, aceitam a tradição da harmonia estéril dos documentos multilaterais.

No entanto, houve alguns sinais positivos, surgidos de fora dos canais estatais tradicionais. Uma primeira dimensão positiva da Cúpula relaciona-se ao papel dos atores não governamentais - particularmente várias organizações empresariais, associações científicas, ONGs com agendas embasadas cientificamente e redes de jornalistas e artistas. Houve aproximadamente 3500 eventos paralelos à agenda oficial, sendo a maioria deles de boa qualidade. Várias conferências empresariais internacionais promoveram declarações em favor de uma transição para uma EVBC, o que mostrou o compromisso genuíno de algumas firmas. Já o Fórum de ONGs mais radicais, reunido na autodenominada Cúpula dos Povos, teve um papel bastante limitado, particularmente se comparado com o destacado papel do Fórum de ONGs na Rio 92.

Uma segunda dimensão positiva da Cúpula - e talvez a mais relevante do ponto de vista de resultados concretos - foi o Fórum das Grandes Cidades, no qual se agruparam 56 das principais cidades do mundo que representam todos os países importantes. Lideradas pelo prefeito de Nova York, Michael Bloomberg, as metrópoles assumiram substantivos e formalizados compromissos de redução de emissões de carbono. Estes 
compromissos estão longe de serem suficientes para lidar efetivamente com a mitigação da mudança climática. No entanto, diante das perspectivas difíceis de negociar algum tipo de extensão relevante do Protocolo de Quioto na $18^{\text {a }}$ Conferência das Partes das Nações Unidas sobre o Clima (COP 18), em Catar, em novembro de 2012, tais compromissos constituem-se, neste ano, no único acordo internacional substantivo entre atores relevantes com o objetivo de acelerar a transição para uma economia mundial de baixo carbono.

Todos esses movimentos fortalecem as redes reformistas de sustentabilidade e incrementam seu nível de impacto sobre a construção de uma sociedade sustentável em escala global no meio prazo. No entanto, o esforço desses agentes não tradicionais foi insuficiente para alterar a lógica intergovernamental na própria Cúpula (nesse sentido, na Rio 92 os atores não estatais tiveram mais impacto sobre o encontro) e muito menor para desbloquear o sistema.

Em relação ao papel do Brasil, houve, nos meses prévios à Cúpula, certo exagero local em relação às possibilidades de o país influenciar significativamente o rumo das negociações, baseado no fato de ser, ao mesmo tempo, uma potência ambiental e o anfitrião do evento. Não obstante, estava claro desde o início que um desbloqueio do sistema estava além das capacidades não apenas do Brasil, mas de qualquer outro ator individual.

Ainda considerando esse limite estrutural, a posição brasileira foi conservadora e pouco contribuiu para gerar algum consenso em torno da proteção dos recursos comuns da humanidade, reforçando seu papel como potência ambiental subdesenvolvida. Em contraste com os desenvolvimentos positivos de 2009-2010 , o Brasil procurou separar o debate da mudança climática, tentando diluir o componente ambiental do evento, enfatizando o componente social, como ficou claro no documento oficial lançado em novembro de 2011 (BRASIL, 2011), que enfatizava a importância do Programa Bolsa Família, mas não fazia menção à lei de clima (Lei n. 12.187, de 29 de dezembro de 2009). A falta de compromisso do governo brasileiro com a gestão do desenvolvimento sustentável ficou evidente quando, no mesmo dia do término da Conferência, a administração Dilma anunciou a redução para zero da contribuição de intervenção no domínio econômico (CIDE) para petróleo e derivados.

Em relação à dinâmica processual da negociação, o Brasil optou pelo caminho de menor risco, evitando colocar-se como o mediador da Conferência e contribuir para a produção de um documento mais ambicioso, derrotando os setores mais conservadores. Pelo contrário, optou pelo consenso a qualquer preço, por um documento sem maior relevância, que apenas ratifica o que foi acordado 20 anos atrás, quando o risco de uma disrupção ambiental global era muito menor. Em definitivo, o Brasil foi incapaz de abandonar uma posição soberanista, comum à grande maioria dos países (com exceção da UE, pequenos estados-ilhas e alguns outros poucos), em defesa mesquinha dos interesses nacionais e insistindo na tradicional tendência de se alinhar automaticamente com os países emergentes e pobres.

Uma dimensão impossível de avaliar antes da passagem de dois a três anos será o legado da Conferência à sociedade brasileira. Nesse aspecto, a Rio 92 teve um profundo legado no país porque contribuiu para aumentar extraordinariamente a consciência ambiental da sociedade brasileira. Terá a Rio 2012 um impacto similar fortalecendo as forças sociopolíticas reformistas decarbonizantes e impulsando a implementação consistente da lei de mudança climática e o abandono do recente curso de política industrial e energética favorável ao complexo automobilístico-petroleiro? Ou o impactoda exposição ampliada da sociedade brasileira aos temas do desenvolvimento sustentável tende a diluir-se devido ao extraordinário poder econômico e de cooptação do núcleo governamental favorável ao desenvolvimento convencional?

5 O documento original do Brasil (2011) é muito atrasado em relação aos avanços da política climática nos anos de 2009 e 2010 , expressados na grande diminuição do desmatamento da Amazônia a partir de 2005; na assunção do compromisso voluntário de dramática redução da curva de crescimento de emissões em novembro de 2009, e na criação da lei de mudanças climáticas. 


\section{O Brasil e a Gestão Local dos Limiares Planetários}

Nos segmentos prévios abordamos a EVBC como instrumento de gestão do espaço seguro de operação da humanidade e destacamos os obstáculos que a atual arquitetura internacional coloca à governança cooperativa das fronteiras planetárias, assumidas como bens comuns universais. Nessa seção fazemos uma avaliação do estado da economia verde de baixo carbono no Brasil por duas vias, primeiro analisando certos pressupostos básicos que a política deve ter para sustentar o desenvolvimento do novo paradigma e, segundo, efetuando uma análise por setor, tendo como referência os 9 limiares planetários.

\section{Condições políticas básicas para a economia verde de baixo carbono}

As condições políticas básicas têm caráter de pressuposto, não resultam necessariamente no avanço de uma economia verde de baixo carbono, sem elas, no entanto, esse desenvolvimento é impossível. No sentido mais profundo, essas condições políticas habilitantes, quando instaladas, tendem a privilegiar a lógica universal (bem público) e de longo prazo sobre a lógica particular (setorial, corporativa) e de curto prazo - o que representa a concepção mesma da sustentabilidade. A lógica atual do sistema político brasileiro, no entanto, obstaculiza qualquer desenvolvimento significativo da economia verde, em virtude de sua incapacidade de agregar a extrema fragmentação de interesses setoriais imperante, e o extremado foco em objetivos de curto prazo.

Desse modo, na concepção atual de desenvolvimento no Brasil, prioriza-se absolutamente o pilar econômico, deixando-se em segundo lugar o pilar social, e em último o pilar ambiental. Nos países mais reformistas (Alemanha, países escandinavos, Coreia do Sul, onde a lógica do bem comum de longo prazo está mais assimilada), o pilar ambiental ocupa o lugar prioritário junto com o pilar de crescimento econômico. É esse o caminho para assegurar uma gestão exitosa da problemática das fronteiras planetárias, a elevação da problemática do espaço seguro de operação da humanidade ao primeiro lugar da agenda do desenvolvimento. Essa transição, no entanto, envolve diferentes velocidades e intensidades, conforme as características socioeconômicas dos países, como já destacamos.

Essa estrutura hierárquica de pilares em relação à economia verde situa o Brasil como potência ambiental subdesenvolvida, já que os recursos naturais abundantes do país facilitam uma economia de baixo carbono, e a metade do território está ocupada por um ecossistema prístino, rico em água e biodiversidade, porém, na política e na sociedade, a assimilação do vetor ambiental é pouco densa.

O sensível retrocesso do eixo ambiental na concepção do desenvolvimento do governo federal brasileiro com a eleição de Dilma Rousseff é mais uma expressão dessa condição estrutural que privilegia o curto prazo e os interesses setoriais, sacrificando o bem-estar futuro por ganhos imediatos. Várias ações da administração iniciada em 2011 sustentam a crítica frequente de grupos preocupados com a agenda ambiental no Brasil: a progressiva transferência do policiamento da Amazônia da área federal (IBAMA) para a esfera estadual e municipal, a redução dos limites de sete áreas de proteção ambiental para construção de barragens e outras obras de infraestrutura, a estagnação do processo de criação de áreas de preservação, e a compulsão por realizar o polêmico projeto de Belo Monte, custe o que custar.

O raciocínio que justifica tais tipos de medida é claro: eliminar qualquer obstáculo ao crescimento para produzir riqueza e tirar milhões de pessoas da pobreza. Esse argumento tem forte apelo na população brasileira e é convergente com os interesses da maior parte do empresariado do país. Como afirma a exministra Marina Silva: "Este é um governo disposto a sacrificar os recursos de milhares de anos pelo lucro de algumas décadas" (PRADA, 2012).

Em agosto de 2012, o governo federal deu um grande salto ao reconhecer a necessidade de um novo paradigma para enfrentar o déficit da infraestrutura do país, quebrando assim a tradição estatista do Partido dos Trabalhadores (PT). O plano prevê, no curto prazo, concessões de mais de uma centena de milhões de 
reais distribuídos em quatro setores: rodovias, ferrovias, portos e aeroportos. As novas medidas foram previamente negociadas com grandes empresas nacionais interessadas nos projetos e com capital suficiente para levá-los adiante, fato que torna provável que o detalhamento do plano será suficientemente atrativo para o setor privado. Este novo paradigma, combinado com a baixa da taxa de juros reais na economia, tende a consolidar o desenvolvimento de um mercado privado de capitais de longo prazo.

Se implementado de forma eficiente, o plano implicará, no meio prazo (cinco anos), uma melhora gigantesca da infraestrutura brasileira, que arrasta um deficit profundo desde, pelo menos, a década de 1990. Pelo que se conhece até o momento, as concessões terão um impacto modernizador convencional sobre a economia do país, já que apenas os investimentos na infraestrutura ferroviária são convergentes com a economia verde de baixo carbono. Nos três setores restantes, poderá haver algum impacto positivo em termos de emissão de $\mathrm{CO} 2$ e poluentes em virtude de aumento na eficiência energética de derivados, principalmente da redução da defasagem entre número de veículos e qualidade e quantidade de rodovias.

No entanto, o pacote de concessões deixa dois grandes buracos: hidrovias e transporte e mobilidade urbana. Neste último caso, embora a atribuição prioritária seja de estados e municípios, o governo federal deveria ter um grande papel impulsor para quebrar a lógica inercial. Promover o transporte público de massa, (metrôs de superfície, trens suburbanos, corredores exclusivos de ônibus) é fundamental para descarbonizar a economia brasileira e aumentar a qualidade de vida da população.

Listamos a seguir algumas das características da democracia brasileira que conspiram contra um maior compromisso com a economia verde de baixo carbono, as primeiras quatro são de caráter estrutural e, portanto, mais importantes e difíceis de mudar, as outras três são, em boa medida, expressão dessa estrutura:

- sistema político extremamente fragmentado e pouco representativo. Sistema multipartidário altamente fragmentado, oligárquico e personalista, profundamente contraditório com uma economia verde de baixo carbono. A existência de inúmeros poderes de veto acaba mitigando ou esterilizando a construção de bens universais;

- educação de baixa qualidade, ineficiente e atrasada. Essas condições favorecem o particularismo e não a procura por interesses universais, que são mais complexos de perceber e assimilar;

- organização burocrática estatal hipertrofiada, compartimentalizada, corrupta e ineficiente, cujo critério principal de organização e funcionamento não é o mérito, mas a distribuição de poder entre as forças políticas. No estamento burocrático o funcionário não opera como servidor público, mas se serve da sociedade para seu próprio interesse, subvertendo os objetivos da função;

- baixo investimento público em ciência e tecnologia, em proporção ao PIB;

- sistema tributário complexo, regressivo e ineficiente, com altíssima carga tributária para uma economia de renda média. O sistema carece de consistência interna - que eleva enormemente os custos de transação - em virtude de ser uma agregação de respostas de curto prazo estimuladas por diferentes conjunturas econômicas. O princípio geral que guia a cultura tributária é atrasado: a extração de recursos da sociedade;

- política externa conservadora; com graus variáveis de soberanismo, conforme os interesses circunstanciais envolvidos: absoluto em relação às grandes potências do pós-guerra mundial, e relativo quando a pretensão brasileira de liderança do mundo desenvolvido, que é uma forma de pós-soberanismo, aparece em cena; e isolada da sociedade até a década de 1990, com abertura progressiva reticente a partir daqueles anos. Em relação ao meio ambiente e sustentabilidade, a política brasileira tende a sobredimensionar o peso do capital ambiental físico do país, apresentando um discurso excessivamente otimista tanto em relação ao nível de agência do Brasil na governança ambiental, quanto em relação aos aportes feitos à sustentabilidade do sistema terrestre; 
- estagnação do gasto público ambiental (e aumento de gasto em infraestrutura) (YOUNG, 2012);

- falta de implementação do protocolo verde de 1995 para instituições financeiras públicas (que são as que mais participam do financiamento à formação bruta de capital fixo, especialmente o Banco Nacional de Desenvolvimento Econômico e Social - BNDES) (YOUNG, 2012).

\section{Economia verde de baixo carbono: diagnóstico por área}

As condições básicas de fragmentação e imediatismo listadas no segmento anterior têm um correlato natural nas políticas setoriais específicas, que são em geral pouco ambiciosas e raramente bem articuladas, embora existam algumas experiências positivas, tais como ${ }^{6}$ :

- pagamento a produtores de água;

- compensação ambiental (Sistema Nacional de Unidades de Conservação);

- compensação financeira e fundos de ciência e tecnologia;

- fundo de reposição florestal e concessões florestais;

- isenção de imposto sobre a propriedade territorial rural (ITR) para Reservas Privadas do Patrimônio Natural (RPPNs);

- ICMS ecológico;

- mercados de carbono - Redução de Emissões por Desmatamento e Degradação florestal (REDD);

- compras públicas sustentáveis;

- bolsa floresta e bolsa verde.

Damos continuidade ao diagnóstico do estado da economia verde de baixo carbono e das políticas relativas no Brasil conforme os 9 limiares planetários, discriminando entre sinais positivos e negativos. Como será possível perceber, existe um desequilíbrio no tratamento de cada um dos limiares, que se deve às características próprias de cada fronteira e à situação particular do Brasil em relação a cada uma delas. Desse modo, o limiar das mudanças climáticas se destaca no diagnóstico por ser a base da definição da EVBC e por ter o Brasil um papel relevante no ciclo global de carbono (BRASIL, 2010).

\section{Limiar 1 - mudança climática - ciclo do carbono}

\section{Positivo}

- Lei Nacional de mudanças climáticas (12.187), que estabelece a Política Nacional de Mudanças Climáticas (PNMC) e incorpora o compromisso voluntário de redução de trajetória de emissões assumido na 15 COP, realizada em Copenhague em dezembro de 2009. Seguindo as diretrizes da lei, o Governo iniciou a regulamentação em 2010 com base nos cinco planos setoriais correspondentes aos compromissos apresentados na COP 15 (conforme Tabela 1): 1. Plano de Ação para a Prevenção e Controle do Desmatamento na Amazônia Legal; 2. Plano de Ação para a Prevenção e Controle do Desmatamento no Cerrado; 3. Energia; 4. Agropecuária; 5. Substituição do Carvão de Desmatamento por Florestas Plantadas na Siderurgia.

\footnotetext{
${ }^{6}$ Young (2012).
} 
Tabela 1

Proposta de redução de trajetória de emissões brasileira

\begin{tabular}{|c|c|c|c|c|c|}
\hline Ações de Mitigação & $\begin{array}{l}2020 \\
\text { Tendencial }\end{array}$ & $\begin{array}{r}\text { Am } \\
\text { reduç } \\
\text { (mi }\end{array}$ & $\begin{array}{l}\text { e da } \\
\text { a } 2020 \\
\left.\mathrm{O}_{2 \mathrm{e}}\right)\end{array}$ & \multicolumn{2}{|c|}{$\begin{array}{l}\text { Proporção de } \\
\text { Redução }\end{array}$} \\
\hline Uso da terra & 1084 & 669 & 669 & $24,7 \%$ & $24,7 \%$ \\
\hline $\begin{array}{l}\text { Desmatamento na Amazônia (redução de } \\
\qquad 80 \% \text { ) }\end{array}$ & - & 564 & 564 & $20,9 \%$ & $20,9 \%$ \\
\hline $\begin{array}{l}\text { Desmatamento no Cerrado (redução de } \\
\qquad 40 \% \text { ) }\end{array}$ & - & 104 & 104 & $3,9 \%$ & $3,9 \%$ \\
\hline Agropecuária & 627 & 133 & 166 & $4,9 \%$ & $6,1 \%$ \\
\hline Recuperação de Pastos & - & 83 & 104 & $3,1 \%$ & $3,8 \%$ \\
\hline ILP - Integração Lavoura-Pecuária & - & 18 & 22 & $0,7 \%$ & $0,8 \%$ \\
\hline Plantio Direto & - & 16 & 20 & $0,6 \%$ & $0,7 \%$ \\
\hline Fixação Biológica de Nitrogênio & - & 16 & 20 & $0,6 \%$ & $0,7 \%$ \\
\hline Energia & 901 & 166 & 207 & $6,1 \%$ & $7,7 \%$ \\
\hline Eficiência Energética & - & 12 & 15 & $0,4 \%$ & $0,6 \%$ \\
\hline Incremento do uso de biocombustíveis & - & 48 & 60 & $1,8 \%$ & $2,2 \%$ \\
\hline $\begin{array}{c}\text { Expansão da oferta de energia por } \\
\text { hidroelétricas }\end{array}$ & - & 79 & 99 & $2,9 \%$ & $3,7 \%$ \\
\hline $\begin{array}{c}\text { Fontes Alternativas ( } \mathrm{PCH} \text {, bioeletricidade, } \\
\text { eólica) }\end{array}$ & - & 26 & 33 & $1,0 \%$ & $1,2 \%$ \\
\hline Outros & 92 & 8 & 10 & $0,3 \%$ & $0,4 \%$ \\
\hline $\begin{array}{l}\text { Siderurgia - substituir carvão de desmate } \\
\text { por plantado }\end{array}$ & - & 8 & 10 & $0,3 \%$ & $0,4 \%$ \\
\hline TOTAL & 2703 & 975 & 1052 & $36,1 \%$ & $38,9 \%$ \\
\hline
\end{tabular}

Fonte: BRASIL, 2009.

Para uma segunda etapa, ficou o processo de regulamentação dos outros planos setoriais: 1. Transportes (cargas e passageiros); 2. Indústria de Transformação e de Bens de Consumo Duráveis; 3. Indústria Química Fina e de Base; 4. Indústria de Papel e Celulose; 5. Mineração; 6. Indústria da Construção Civil; e 7. Serviços de Saúde.

- Lei de mudanças climáticas do Estado de São Paulo (lei estadual no 13.798, de 9 de novembro de 2009), que estabelece metas de redução de emissões de $20 \%$ em 2020 , com relação ao ano de 
referência, 2005. Esta lei é explicitamente obrigatória e sua aplicação toca principalmente nos setores de energia, indústria e transportes, razão pela qual sua implementação representa um desafio maior que a lei nacional.

- Redução de desmatamento entre 2005 e 2011.

Figura 1

Evolução anual do desmatamento na Amazônia: 1988-2011 (km²)

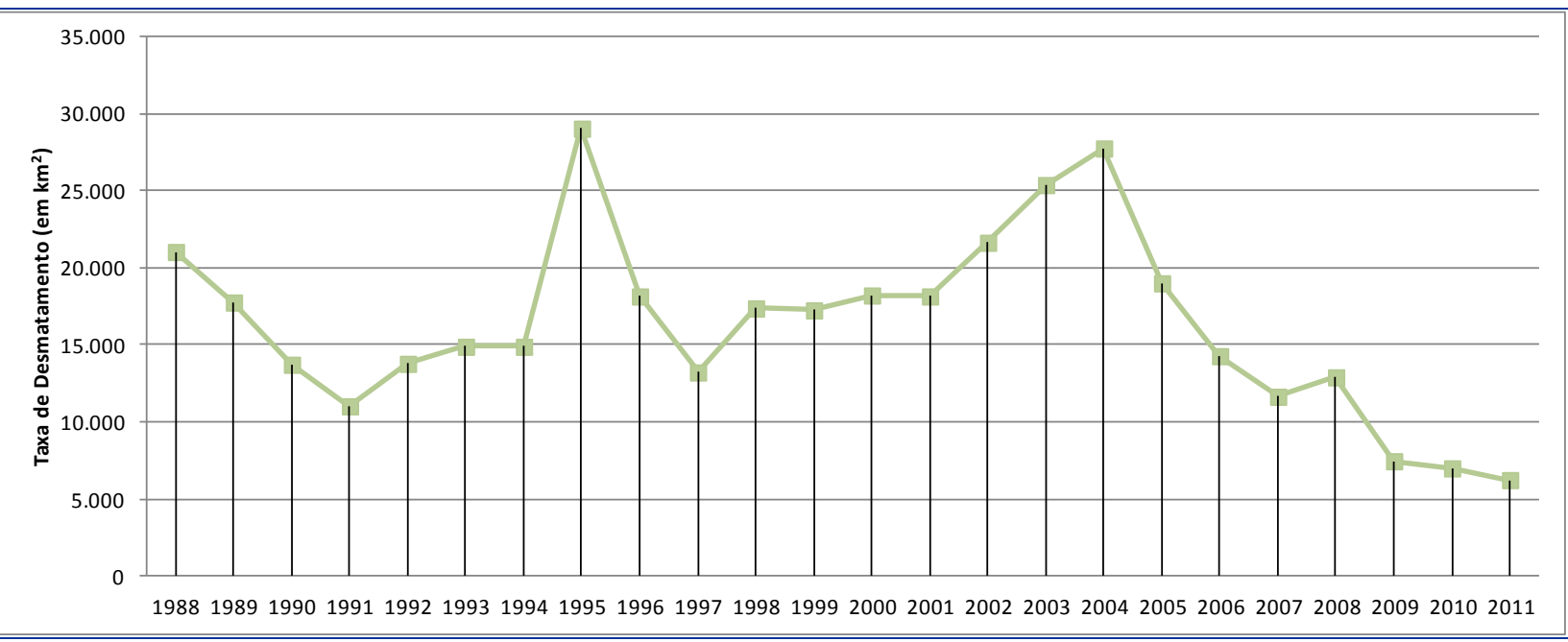

Fonte: Programa de Cálculo do Desflorestamento da Amazônia (PRODES)-Instituto Nacional de Pesquisas Espaciais (INPE) ${ }^{7}$.

- Criação do Fundo Amazônia (MOUTINHO, 2012).

- Programa de etanol. O programa foi lançado com elevados subsídios na década de 1970 - com motivações de segurança energética no âmbito do modelo de substituição de importações. Responde por aproximadamente $17 \%$ da matriz energética brasileira e sem ele as emissões do país seriam aproximadamente $15 \%$ superiores. A introdução da tecnologia flex-fuel permitiu a expansão do etanol na década de 2000 , no entanto, sua eficiência é baixa e precisa ser aprimorada, se incorporados estímulos corretos.

- Avanço do Plantio Direto.

- Plano de Agricultura de Baixo Carbono (ABC). Os recursos disponibilizados foram pouco utilizados pelos produtores, e em maior proporção por grandes produtores, que já têm níveis de eficiência maiores em relação aos pequenos.

- Incipiente avanço da energia eólica, favorecida por subsídios e leilões específicos para fontes renováveis entre 2009 e 2011 (SCHAEFFER et al. 2012).

- Linhas de financiamento do BNDES para energias renováveis.

- Programa de Incentivo às Fontes Alternativas de Energia Elétrica (Proinfa).

${ }^{7}$ http://www.obt.inpe.br/prodes/prodes_1988_2011.htm 
- Políticas públicas de incentivo à eficiência energética: Programa Nacional de Conservação de Eletricidade (PROCEL) e Programa Nacional de Racionalização do Uso dos Derivados do Petróleo do Gás Natural (COMPET). Não tiveram grande impacto sistêmico.

- Retomada dos investimentos em energia hidroelétrica, de forma mais sustentável que no passado, embora com algumas dúvidas em relação à eficiência da substituição de reservatórios por fio de água. Nesse sentido, houve um trade-off negativo entre impacto ambiental local e segurança energética.

- Entre 2000 e 2008, o percentual de resíduos sólidos urbanos dispostos de forma inadequada (lixões, aterro controlado) passou de 57 para 42\% (GARCIA, 2012).

- Lei 12.305, de agosto de 2010, estabelece a Política Nacional de Resíduos Sólidos (GARCIA, 2012).

- Programa de Compras Públicas Sustentáveis do Estado de São Paulo vigente desde 2010 e que estimulou o governo federal a adotar um programa similar em 2012, embora menos ambicioso.

- Certo avanço de greenbuilding em São Paulo e Rio de Janeiro, ainda incipiente, mas importante em relação aos padrões globais.

\section{Negativo}

- Mínimo avanço dos planos setoriais da PNMC. Os planos que já estão em fase relativamente avançada de implementação e com resultados concretos - Amazônia e Cerrado - já vinham sendo desenvolvidos antes da aprovação da Lei de Clima. Parte do plano de agricultura também está em andamento - Plano Agricultura de Baixo Carbono (ABC) -, embora os produtores ainda não se inclinem a utilizar os créditos disponíveis. $O$ plano de energia apresenta grandes incertezas, especialmente em relação ao rumo das hidrelétricas na Amazônia, e o plano de siderurgia encontra-se ainda em etapa de desenvolvimento. Os outros sete planos estão numa espécie de limbo, já que são muito difíceis de serem negociados com os setores, têm grandes obstáculos para sua implementação e não têm o suporte de atores políticos e societais relevantes.

- Política industrial inspirada no paradigma clássico de crescimento, com baixa sensibilidade para questões ambientais.

- Estímulo ao transporte individual e ao modal rodoviário na política de transportes (BALASSIANO, 2012; CONFEDERAÇÃO NACIONAL DO TRANSPORTE, 2011):

- aumento da frota circulante de carros particulares nas cidades (congestionamento, emissões, poluição sonora, acidentes, tempo de viagem);

- falta de política coerente entre municípios de áreas metropolitanas;

- predomínio do modal rodoviário para transporte de cargas;

- infraestrutura insuficiente e deteriorada;

- elevada idade da frota de caminhões e combustíveis com altos níveis de enxofre;

- baixo investimento público em infraestrutura nas últimas três décadas ( $2 \%$ em 1970 , $0,2 \%$ até 2007 e $0,74 \%$ até 2010 ).

- Subsídio ao preço da gasolina, tendo como exemplo recente a referida eliminação da CIDE para derivados do petróleo em junho de 2012.

- Megacapitalização da Petrobras tendo em vista a exploração das reservas do Pré-Sal.

- Abandono da política de estímulo ao etanol a partir de 2007, acompanhado do esgotamento dos benefícios do motor flex para a expansão do combustível. 
- Ausência de políticas de adaptação no contexto de uma cultura de defesa civil precária.

- Reforma do Código Florestal.

- Falta de elaboração do Plano Nacional de Resíduos Sólidos (RS).

- Baixa proporção de Resíduos Sólidos Urbanos (RSU) reciclados (30 \%) (GARCIA, 2012).

\section{Limiar 2 - ciclo do nitrogênio e fósforo}

\section{Positivo}

- Plano ABC.

- Avanço do Plantio Direto.

\section{Negativo}

- Excesso de utilização de fertilizantes por ha, que eleva o ritmo da produção agrícola (5 a 4 \%). O Brasil é o segundo consumidor mundial de fertilizantes (DELGADO ASSAD, MARTINS e SILVEIRA PINTO, 2012).

\section{Limiar 3 - acidificação dos oceanos}

\section{Positivo}

- Iniciativa brasileira de governança dos oceanos na Rio+20.

\section{Negativo}

- Grande destruição de manguezais.

\section{Limiar 4 - Biodiversidade}

\section{Positivo}

- Redução do desmatamento na Amazônia.

- Controle quase total do desmatamento na Mata Atlântica, avanço do estado de direito no bioma, com exceção da lei estadual de Santa Catarina (Lei no 14.675, de 13 de abril de 2009).

- Avanço na criação de áreas de preservação nos últimos 15 anos, especialmente na Amazônia, embora com problemas de enforcement.

- Normativa rígida de tráfico de espécies, embora com sérios problemas de aplicação.

- Posição de liderança do Brasil na aprovação do Protocolo de Nagoya, em 2010, apresentando posições relativamente universalistas no aproveitamento dos recursos da biodiversidade.

\section{Negativo}

- Desmatamento remanescente na Amazônia e no Cerrado.

- Intenso tráfico de espécies ameaçadas e não ameaçadas. 
- Reforma do Código Florestal.

- Concepção paranoica da biopirataria, com bloqueio a um uso mais racional dos recursos da biodiversidade por meio da pesquisa científica.

- Baixo desenvolvimento tecnológico derivado da biodiversidade, em razão de uma concepção soberanista e defensiva - que começou a mudar recentemente - na gestão dos recursos biológicos.

- Agricultura transgênica ilegalmente desenvolvida, e posteriormente imposta como fato consumado, expressão da distância entre norma e realidade. Aproximadamente 25 milhões de hectares estão plantados com transgênicos (DELGADO ASSAD, MARTINS e SILVEIRA PINTO, 2012).

\section{Limiar 5 - água doce}

\section{Positivo}

- Criação por lei do Sistema Nacional de Recursos Hídricos.

- Programa "Produtor de Água", da ANA, pago por serviços ambientais para recursos hídricos (RAMOS e FORMIGA-JOHNSSON, 2012).

- Lei de Resíduos Sólidos e melhora na disposição final de RSU.

\section{Negativo}

- Implementação limitada do Plano Nacional de Recursos Hídricos de 2006.

- Contaminação por mercúrio das águas da Amazônia, cujo vetor principal é o garimpo.

- Degradação de oferta hídrica de qualidade em regiões densamente povoadas, como resultado de: baixo percentual de esgotos tratados $(50 \%)$, disposição inadequada de resíduos sólidos, impermeabilização crescente do solo urbano e comprometimento de mananciais (LOBATO, 2012).

- Falta de elaboração do Plano Nacional de RS, baixa proporção de RSU reciclados $(30 \%)$ (GARCIA, 2012).

- Deterioração de águas superficiais por consumo de agrotóxicos (herbicidas, inseticidas e fungicidas). O Brasil foi o maior consumidor mundial desse tipo de produto em 2008 (DELGADO ASSAD, MARTINS e SILVEIRA PINTO, 2012).

- Escassez de água em certas regiões.

- Impacto da irrigação para agricultura sobre a oferta de água, já que a atividade consume $60 \%$ do total (DELGADO ASSAD, MARTINS E SILVEIRA PINTO, 2012).

- Indústria da seca no semiárido do Nordeste, agregando ineficiência na administração de recursos e altos níveis de corrupção.

- Contaminação e sobre-exploração em algumas zonas do Aquífero Guarani por gestão improvisada.

- Hidroelétricas a fio d'água.

- Impacto de doenças de veiculação hídrica, vinculado a falta de esgoto e deficientes condições de higiene. 


\section{Limiar 6 - mudanças no uso da terra}

\section{Positivos}

- Redução do desmatamento na Amazônia.

- Expansão do Plantio direto.

- Aumento de produtividade da agricultura ${ }^{8}$ familiar nas últimas duas décadas (SILVEIRA PINTO et al., 2012).

- Função modernizadora da Embrapa e das agências estaduais de extensão rural.

- Avanço na criação de áreas de preservação nos últimos 15 anos.

- Carvão de reflorestamento para indústria siderúrgica.

\section{Negativo}

- Desmatamento remanescente.

- Reforma do Código Florestal.

- Conversão não planificada da floresta.

- Utilização de mata nativa para produção de carvão vegetal (carvoejamento), geralmente usado em indústrias periféricas e em condições ambientais e laborais extremamente precárias.

- Pouco reflorestamento e florestamento em terras degradadas.

- Agrossilvicultura pouco explorada nas terras convertidas (VALVERDE et al, 2012), oposto do exemplo do cacau no Estado da Bahia.

- Excesso de utilização de agrotóxicos.

- Urbanização desordenada, que é pouco importante em termos de disponibilidade de terras, mas fundamental para a qualidade de vida.

- Processo de desertificação no semiárido do Nordeste.

\section{Limiar 7 - ozônio}

\section{Positivo}

- Atitude cooperativa no banimento dos clorofluorcarbonos (CFCs).

- Baixa economia clandestina de CFCs.

\section{Limiar 8 - poluição química}

\section{Positivo}

- Aumento sensível dos controles de contaminação em vários estados, especialmente São Paulo.

${ }^{8}$ Existem cinco tipos de agricultura no Brasil: familiar, de baixo impacto; pequena agricultura de baixo carbono; agricultura tradicional em declínio; agricultura moderna intensiva em carbono; e agricultura moderna com tendência para o baixo carbono, incluindo agricultura orgânica. 
- Atitude cooperativa do Brasil na Convenção sobre Poluentes Orgânicos Persistentes (POPs).

\section{Negativo}

- Herança histórica de contaminação com metais pesados. Contaminação massiva por mercúrio em lugares como a cidade de Rio Branco.

- Uso excessivo de químicos na indústria, com padrões sanitários e de segurança pouco exigentes.

- Excesso de utilização de agrotóxicos.

- Incidência de doenças cardiorrespiratórias em grandes cidades.

\section{Limiar 9 - Aerossóis}

\section{Positivo}

- Frota de carros moderna nas grandes cidades.

- Melhora de standards na frota de transporte.

\section{Negativo}

- Avançada idade da frota de transportes rodoviários (FLEURY, 2012).

- Baixa qualidade dos combustíveis, intensivos em enxofre.

- Baixa qualidade da infraestrutura de transportes, desequilibrada em favor do modal rodoviário.

\section{Conclusões}

Para evitar que as próprias ações como espécie levem a humanidade além do domínio estável do Holoceno, é preciso criar mecanismos eficientes de governança global para as fronteiras planetárias. Por enquanto, a humanidade não tem sido capaz de alinhar seu comportamento com sua capacidade de alterar sistemas biofísicos críticos e, como consequência, três limiares planetários têm sido ultrapassados: estabilidade do sistema climático, biodiversidade e ciclo do nitrogênio. Assim, uma desestabilização abrupta do ambiente global aparece como um cenário possível. Este argumento, não incomum na literatura ambiental das últimas décadas, consolida sua relevância nos últimos anos pela acumulação de provas científicas e pela evidência da aceleração de fenômenos físicos e sociais.

O primeiro passo para evitar uma transição catastrófica para o Antropoceno é iniciar o caminho para um paradigma de desenvolvimento global que garanta um espaço de operação segura para a humanidade chamamos a esse modelo de economia verde de baixo carbono. A EVBC tem como base processos produtivos e de consumo pouco intensivos em carbono, complementados com uma gestão racional de outros recursos, como água, terra, biodiversidade, etc.

A gestão de um espaço de operação segura para a humanidade oferece, no entanto, grandes desafios. Na medida em que as fronteiras planetárias operam como global commons, demandam necessariamente respostas cooperativas de parte da comunidade internacional. Esse tipo de resposta não é incomum na história da humanidade, mas a escala do esforço demandado e o fato de a crise ser incremental e com efeitos mais evidentes no longo prazo conspiram contra uma administração conjunta do problema. Como afirmamos, a humanidade apenas reage a ameaças imediatas muito tangíveis ou à imoralidade extrema e, em virtude disso, as instituições sociais estão criadas para funcionar dentro do horizonte do curto prazo. 
O infeliz resultado da Rio+20 é evidência clara dessa defasagem entre a aceleração dos problemas da interdependência global e a incapacidade das elites políticas do mundo para articular respostas eficientes. A Rio+20 é também expressão de um sistema internacional bloqueado, dominado por forças soberanistas e conservadoras, reticentes a ceder poder e renunciar a interesses de curto prazo para contribuir na construção de bens públicos globais sustentáveis.

No debate sobre a governança dos limiares planetários, o Brasil aparece como um agente relevante, uma potência ambiental por seu capital físico: recursos hídricos, biodiversidade, terras cultiváveis, grande proporção do seu território ocupado por um ecossistema prístino.

No entanto, o Brasil avançou pouco na transição para uma EVBC, apesar dessas enormes possibilidades. O desmatamento remanescente e o ainda intenso e improvisado processo de conversão das florestas pressionam os limites da água, uso da terra, biodiversidade e clima. O caótico e declinante estado do setor de transportes de carga e público, o estímulo ao transporte individual e os subsídios federais à gasolina têm efeitos negativos sobre o ciclo do carbono, a poluição química e a liberação de aerossóis na atmosfera. $O$ incentivo oficial à massiva exploração de petróleo, o desincentivo ao etanol e as dúvidas sobre as novas hidroelétricas a fio d'água contribuem para agravar a questão climática e o uso da água. $O$ abuso na utilização de agrotóxicos e fertilizantes contribuem para a poluição química, emissões de GEE e contaminação das águas superficiais e subterrâneas. Efeitos similares tem a deficiente gestão da disposição final de resíduos.

A evolução da implementação da lei de clima de 2010 é provavelmente o parâmetro mais claro do estado da agenda da EVBC no Brasil. A normativa foi extremamente relevante visto que: foi única em seu momento entre os países fora da Organização para a Cooperação e Desenvolvimento Econômico (OCDE); marcou o ápice da agenda ambiental no Brasil, estimulada pelo sucesso da política de controle do desmatamento na Amazônia; abrangeu áreas centrais da economia verde. No entanto, e como vimos, os únicos planos da PNMC que tiveram resultados tangíveis foram os relativos ao desmatamento, que já estavam funcionando antes da sanção da lei.

Ademais, e de forma paradoxal, enquanto a ciência precisa o grau de ameaça antrópica sobre o sistema terrestre, a nova administração federal comandada por Dilma Rousseff é provavelmente a menos sensível às questões ambientais em duas décadas. Como vimos, o modelo de desenvolvimento privilegiado pelo poder executivo - e com altos níveis de aceitação na sociedade e empresariado local - é dominado absolutamente pelo pilar do crescimento econômico.

Por isso, se ao diagnóstico sobre o capital ambiental físico do Brasil incorpora-se uma avaliação do capital ambiental social, o país aparece como uma potência ambiental subdesenvolvida, na qual a EVBC é apenas incipiente. O destacável é que o Brasil tem grandes potencialidades para essa transição de paradigma, e não deveria esperar consequências negativas relevantes no curto prazo, ao contrário, se tornaria um país mais sério e avançaria na convergência estrutural que existe entre o interesse nacional do país e o interesse universal da humanidade. Mas, para isso, é necessária a superação de certos vícios da dinâmica sociopolítica que estimulam uma exagerada concentração no curto prazo e um predomínio dos interesses corporativos particularistas sobre o bem público global.

Infelizmente, a brasileira não é a única sociedade contaminada por uma visão limitada do interesse público e por uma miopia temporal. A maioria dos países opera no campo conservador, inspirada por uma lógica soberanista que impede qualquer avanço significativo na governança global das fronteiras planetárias. 


\section{Referências}

BALASSIANO, R. Mobilidade urbana no âmbito da economia verde. Fundação Brasileira para o Desenvolvimento Sustentável - FBDS, 2012. Disponível em: <http://fbds.org.br/fbds/IMG/pdf/doc-540.pdf>. Acesso em: 25 jun. 2012.

BRASIL. MMA, MAPA, MME, MF, MDIC, MCT, MRE, Casa Civil. Cenários para oferta brasileira de mitigação de $\quad$ emissões. 2009.20 Disponível $<\mathrm{http}: / /$ www.forumclima.pr.gov.br/arquivos/File/CenariosparaOfertaBrasileiradeMitiga.pdf $>$. Acesso em 7 mar. 2011.

. Ministério da Ciência e Tecnologia. Segunda Comunicação Nacional à Convenção-Quadro das Nações Unidas sobre Mudança do Clima, 2010. Disponível em: $<$ http://www.mct.gov.br/index.php/content/view/326988.html>. Acesso em 2 nov. 2010.

Documento de contribuição brasileira à conferência Rio+20. Disponível em: http://www.rio20.gov.br/documentos/contribuicao-brasileira-a-conferencia-rio-20. Acesso em: 15 fev. 2011.

BIERMANN, F. Navigating the Anthropocene: improving earth system governance. Science, v. 335, Mar. 2012.

CONFEDERAÇÃO NACIONAL DO TRANSPORTE. Plano CNT de transporte e logística. 2011. Disponível em: $<$ http://www.cnt.org.br/Paginas/Plano-CNT-de-Log\%C3\%ADstica.aspx>. Acesso em 23: set. 2011.

DELGADO ASSAD, E.; MARTINS, S.; SILVEIRA PINTO, H. Sustentabilidade no agronegócio brasileiro. Fundação Brasileira para o Desenvolvimento Sustentável - FBDS, 2012. Disponível em: $<$ http://fbds.org.br/fbds/IMG/pdf/doc-553.pdf>. Acesso em: 17 jun. 2012.

FLEURY, P. Logística no Brasil: situação atual e transição para uma economia verde. Fundação Brasileira para o Desenvolvimento Sustentável - FBDS, 2012. Disponível em: <http://fbds.org.br/fbds/IMG/pdf/doc-538.pdf $>$. Acesso em: 20 jul. 2012.

GARCIA, E. Resíduos sólidos urbanos e a economia verde. Fundação Brasileira para o Desenvolvimento Sustentável - FBDS, 2012. Disponível em: <http://fbds.org.br/fbds/IMG/pdf/doc-543.pdf>. Acesso em: 27 jun. 2012.

LAMERS, P. et al. International bioenergy, trade - a review of past developments in the liquid biofuels market. Renewable and Sustainable Energy Reviews, v. 15, n. 6, p. 2655-2676, 2011.

LOBATO, F. Recursos hídricos e a economia verde - setor privado. Fundação Brasileira para o Desenvolvimento Sustentável - FBDS, 2012. Disponível em: <http://fbds.org.br/fbds/IMG/pdf/doc-556.pdf>. Acesso em: 20 jun. 2012.

MOUTINHO, P. Redução de emissões por desmatamento e degradação florestal (REDD+): construindo os alicerces da economia verde no Brasil. Fundação Brasileira para o Desenvolvimento Sustentável - FBDS, 2012. Disponível em: <http://fbds.org.br/fbds/IMG/pdf/doc-547.pdfr>. Acesso em 10 jun. 2012.

PACKARD, V. La obsolecencia planeada. Buenos Aires: Editora Paidós, 1964.

PRADA, P. Brasil retrocede em leis federais de proteção à Amazônia. G1 online, Rio de Janeiro, 10 ago. 2012. Disponível em: <http://g1.globo.com/natureza/noticia/2012/08/brasil-retrocede-em-leis-federais-de-protecaoamazonia.html>. Acesso em: 15 ago. 2012.

RAMOS, M.; FORMIGA-JOHNSSON, R. M. Água, gestão e transição para uma economia verde no Brasil propostas para o setor público. Fundação Brasileira para o Desenvolvimento Sustentável - FBDS, 2012. Disponível em: $<$ http://fbds.org.br/fbds/IMG/pdf/doc-558.pdf>. Acesso em: 10 jun. 2012.

ROCKSTRÖM, J. et al. Planetary boundaries: exploring the safe operating space for humanity. Ecology and Society, v. 14, n. 2, p. 32, 2009. Disponível em: <http://www.ecologyandsociety.org/vol14/iss2/art32/>. Acesso em: 12 fev. 2011. 
SCHAEFFER, R. Energia e economia verde: cenários futuros e políticas públicas. Fundação Brasileira para o Desenvolvimento Sustentável - FBDS, 2012. Disponível em: <http://fbds.org.br/fbds/IMG/pdf/doc-545.pdf>. Acesso em: 18 jun. 2012.

SILVEIRA PINTO et al. Diretrizes para uma economia verde no Brasil: avanços tecnológicos para a agricultura familiar. Fundação Brasileira para o Desenvolvimento Sustentável - FBDS, 2012. Disponível em: $<$ http://fbds.org.br/fbds/IMG/pdf/doc-551.pdf>. Acesso em: 15 jun. 2012.

STERN, N. Stern review: la economia del cambio climático. 2006. Disponível em: <http://webarchive.nationalarchives.gov.uk/+/http://www.hm-treasury.gov.uk/sternreview_index.htm>. Acesso em: 9 set. 2009.

VALVERDE, S. R. et al. Silvicultura brasileira - oportunidades e desafios da economia verde. Fundação Brasileira para o Desenvolvimento Sustentável - FBDS, 2012. Disponível em: <http://fbds.org.br/fbds/IMG/pdf/doc-549.pdf>. Acesso em: 30 jun. 2012.

VIOLA, E.; FRANCHINI, M.; LEMOS RIBEIRO, T. Sistema internacional de hegemonia conservadora: governança global e democracia na era da crise climática, São Paulo: Annablume, 2012.

YOUNG, C. E. Setor financeiro: suporte fundamental de transição para a economia verde. Fundação Brasileira para o Desenvolvimento Sustentável - FBDS, 2012. Disponível em: <http://fbds.org.br/fbds/IMG/pdf/doc-561.pdf $>$. Acesso; 20 jun. 2012. 